\title{
STUDIES ON DIURETICS. I. THE SITE OF ACTION OF MERCURIAL DIURETICS ${ }^{1}$
}

\author{
By JOHN J. DUGGAN ANd ROBERT F. PITTS wIth THE TECHNICAL ASSISTANCE OF \\ PHYLLIS MINER AND MARTHA BARRETT
}

(From The Department of Physiology, Syracuse University College of Medicine, Syracuse, N. Y.)

(Received for publication November 19, 1949)

Although it is generally accepted that organic mercurial diuretics depress the renal tubular absorption of sodium, ${ }^{2}$ precise localization of their site of action within the tubule has not been accomplished. If one administers graded doses of such diuretics to the dog it becomes apparent that, above a certain level, further increases in dosage yield progressively diminishing increments of sodium excretion. This pattern of response suggests that these agents depress some specific fraction of total sodium absorption, and that this fraction might be quantitated and the mechanism itself thereby identified by the administration of doses of mercurial diuretics sufficient to block it completely.

The micropuncture studies of Walker and his associates (1) indicate that at least $67 \%$, and probably around $80 \%$ of the glomerular filtrate is reabsorbed isosmotically in the proximal segment of the mammalian nephron. Wesson, Anslow, and Smith (2), studying osmotic diuresis in the dog, have estimated that about $87 \%$ of the filtered sodium is reabsorbed actively by the proximal tubule. If these figures are even roughly correct, some 13 to $33 \%$ of the filtered load must be reabsorbed distally, for under usual conditions, an insignificant fraction of the filtered load is excreted.

We have proceeded in our study on the premise that if mercurial diuretics are capable of blocking the absorption of the larger fraction of the filtered sodium (67 to $87 \%$ ), they must act on the proximal tubule. On the other hand if they block a smaller fraction (13 to $33 \%$ ), whatever the dose

\footnotetext{
1 Aided by grants from the National Heart Institute of the National Institutes of Health and the Life Insurance Medical Research Fund.

2 Throughout this paper we shall speak in terms of the blockage of the active absorption of sodium by mercurial diuretics. Actually we have no evidence that these agents may not block the active absorption of chloride, and that in consequence, equivalent quantities of sodium appear in the urine.
}

administered, they may well act on the distal tubule. This latter conclusion, in contrast to the first, is not incontestable. It is, of course, possible that there might be two or more distinct mechanisms for sodium absorption in the proximal tubule, only one of which is mercury sensitive. That mechanism might account for 16 to $33 \%$ of the total of 67 to $87 \%$ of filtered sodium normally absorbed in the proximal tubule. Since no evidence of functional differentiation of sodium absorption in this segment exists, we incline to the former and simpler interpretation. Our findings demonstrate (a) that there is a specific mechanism for sodium absorption which can be completely blocked by large doses of mercurial diuretics; and (b) because it accounts for 17.1 to $21.4 \%$ of total absorption, this mechanism probably resides in the distal tubule.

\section{METHODS}

Experiments were performed on trained, unanesthetized dogs. Animals were used in the fasting state, at intervals of not less than one week. Glomerular filtration rate was measured by the creatinine clearance and sodium was determined in plasma and urine with an internal standard flame photometer. Other methods have been described in previous communications (3).

\section{RESULTS}

The unprepared, normally hydrated $\operatorname{dog}^{3}$ is not suitable for this study. Presumably the loss of excessive quantities of sodium and water in the urine or the cardiac and vascular toxicity of the diuretic per se so compromises circulatory function that the animal cannot for long maintain a stable renal hemodynamic state. Consistently, the onset of diuresis is followed shortly by a fall in glomerular filtration rate such that the ap-

3 So-called normal hydration was achieved in the initial experiments by administering $300 \mathrm{cc}$. of water by stomach tube approximately one hour prior to the start of the experiment. 


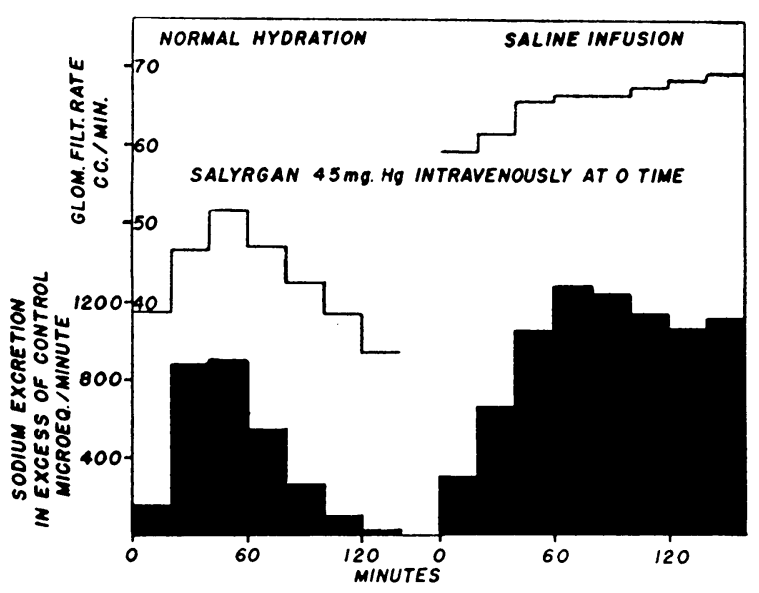

Fig. 1. The Effect of Mercurial Diuresis on Glomerular Filtration Rate in the Normally Hydrated Dog, and in the Same Animal Given a SupPORTED INFUSion OF SALINe

parent duration of action of the diuretic is drastically foreshortened, and its real effectiveness largely masked. This pattern is seen in the experiment at the left in Figure 1, in which creatinine in isotonic glucose was infused throughout the experiment at a rate of $1 \mathrm{cc}$. per minute. No other supportive measures were employed. The rise in filtration rate observed immediately after the intravenous administration of salyrgan is most probably due to an action of the theophylline which it contains. Following the loss of significant quantities of sodium and water in the urine, glomerular filtration rate decreased, and with it, diuresis and sodium excretion. Although the falling filtration rate may protect the animal from excessive depletion of extracellular fluid, the continually varying load of filtrate beclouds any analysis of tubular function. Presumably, a similar mechanism limits the diuresis produced by mercurials in normal humans (4) as contrasted with the copious and protracted diuresis seen in edematous patients.

On the other hand, the infusion of $0.85 \%$ sodium chloride at $10 \mathrm{cc}$. per minute for two and onehalf hours prior to and throughout the course of the experiment provides an adequate backlog of extracellular fluid. As illustrated in the graph on the right, filtration rate not only was initially higher than in the normally hydrated animal but also was satisfactorily maintained despite the loss of larger quantities of sodium and water.

Further, we have not been able to administer intravenously to unprepared dogs any of the commonly used mercurials ${ }^{4}$ in the range of dosage necessary to produce maximal effects (i.e. 100 to $240 \mathrm{mg} . \mathrm{Hg}$ ) without producing an immediate depression of glomerular filtration which is so severe that the technique becomes untenable. A series of experiments in which progressively increasing doses of salyrgan were administered to a normally hydrated dog is illustrated in Figure 2. It is apparent that a drastic effect on filtration rate,

4 Salyrgan, Mercuzanthin, Mercuhydrin.

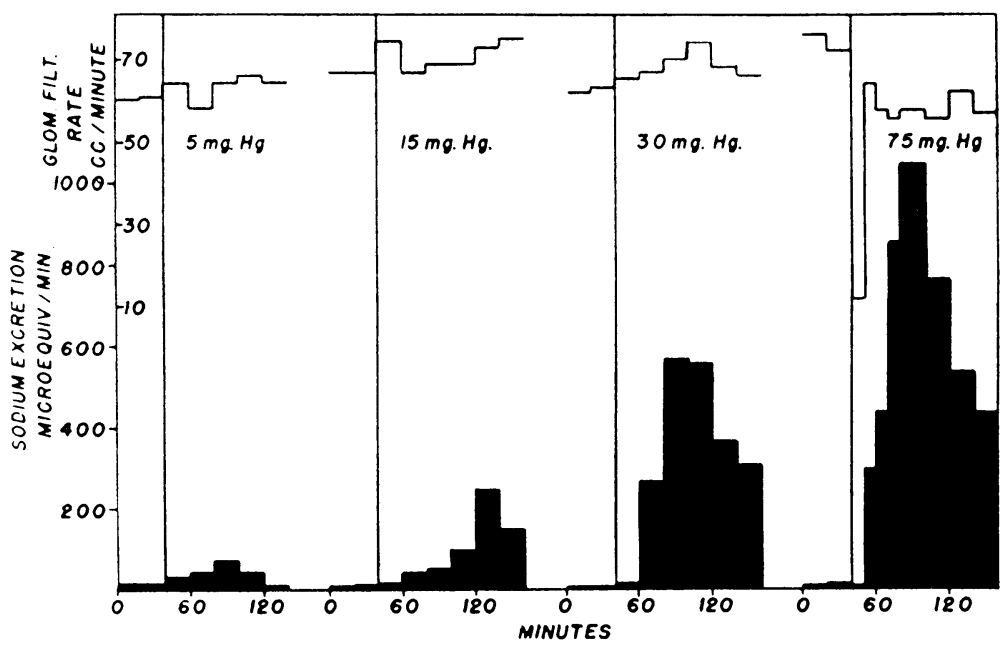

Fig. 2. The Acute Effect on Glomerular Filtration Rate of Graded Intravenous Doses of Salyrgan in a Normally Hydrated Dog

Time of injection indicated by vertical lines. 
with an immediate fall to $12 \mathrm{cc}$. per minute, appeared with a dose of $75 \mathrm{mg}$. Hg before there was any suggestion that sodium excretion was approaching a ceiling. This difficulty was minimized by the use of the supporting infusion of saline with injection of the mercurial at rates not greater than $8 \mathrm{mg}$. $\mathrm{Hg}$ per minute. Ascorbic acid (150 mg.) was incorporated for its protective value (5). High doses of thiomerin led to such marked and progressive diminution of filtration rate that this preparation was not found helpful.

The sodium excretion observed after administration of graded doses of salyrgan to a single dog is presented in Figure 3. An infusion of $0.85 \%$ saline was given for two and one-half hours before, and during the course of each experiment. It is evident that increases in dosage from 15 to $30 \mathrm{mg}$. $\mathrm{Hg}$ and from 30 to $45 \mathrm{mg}$. $\mathrm{Hg}$ were reflected by enhanced sodium excretion. However, the response obtained from $45 \mathrm{mg}$. $\mathrm{Hg}$ was in this animal a limiting one, and was not exceeded even when twice that amount was given. The peak sodium

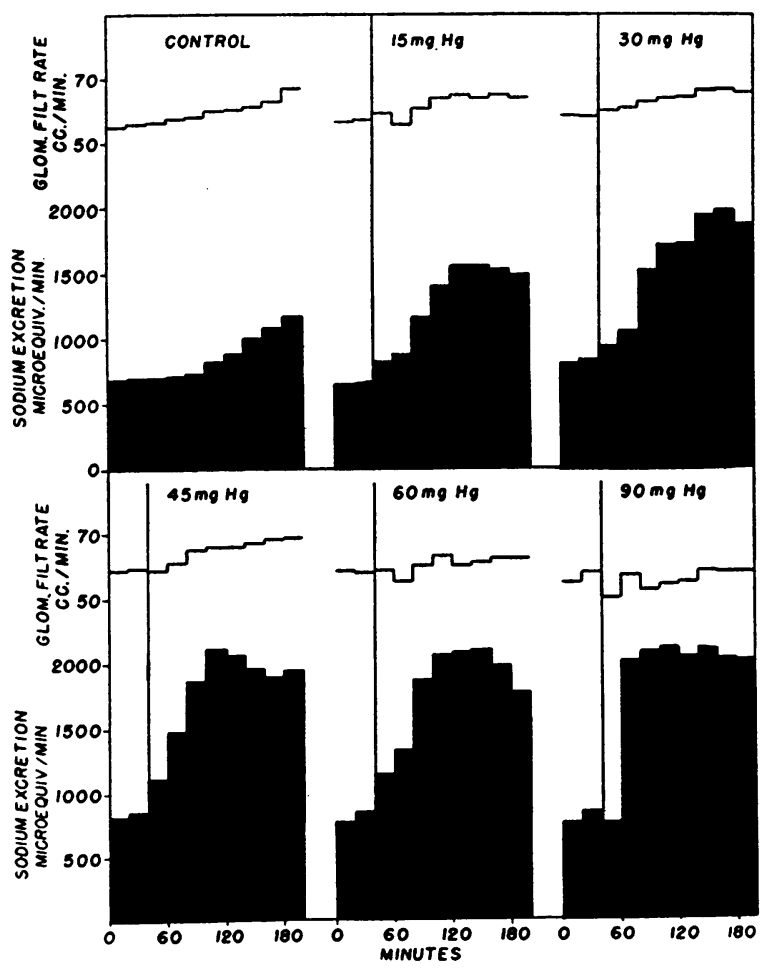

Fig. 3. Sodium Excretion in a Dog Given Graded Doses of Salyrgan

Saline infusion at $10 \mathrm{cc}$. per minute. Time of injection of drug indicated by vertical lines. excretion was reached more quickly with the higher doses and was maintained for a longer time, but its height remained fixed.

When the saline infusion is used the excretion of sodium resulting from the infusion alone is considerable. The effectiveness of a diuretic given in the course of such an infusion must be expressed in terms of the increase in excretion of sodium and water which it produces. It is difficult to establish true control levels. If the infusion is given alone through the usual duration of an experiment, one observes a gradual increase in sodium excretion. This is not surprising, for the animal is in progressively increasing positive salt and water balance throughout, with expanding extracellular fluid volume and progressively rising glomerular filtration rate. If, however, a mercurial is administered, the increment in urine flow is such that the animal is no longer accumulating water and salt. In order to obtain reasonable terminal control levels, BAL was administered in several experiments to block the effect of the diuretic after the peak response had been established (6). In general, with the experimental plan adopted, these terminal control levels agreed closely with initial control levels and were consolidated with them for calculations.

A typical experiment is illustrated in Table $I$. Saline was infused at a rate of $10 \mathrm{cc}$. per minute for two and one-half hours before, and throughout the course of the experiment. During the initial two control periods, roughly 0.8 millimol per minute of sodium was excreted; 10.7 to 11 millimols were reabsorbed. These latter quantities represent $93 \%$ of the filtered moiety. Following the administration of $100 \mathrm{mg}$. $\mathrm{Hg}$ as mercuhydrin, sodium absorption decreased and excretion increased until in the sixth through the eighth clearance periods only $80 \%$ of the filtered sodium was reabsorbed. Glomerular filtration rate and plasma sodium concentration varied but little throughout the entire experiment.

Following the intramuscular administration of $1 \mathrm{cc}$. of $10 \% \mathrm{BAL}$ in oil, sodium excretion dropped to the control level, and the per cent of filtered sodium absorbed returned toward its initial value.

The three experiments summarized in Figure 4 were performed on one dog in the manner just described. Following two or three control periods, mercuhydrin was administered intrave- 
TABLE I

An experiment illustrating the effect of mercurial diuresis on glomerular filtration rate and sodium reabsorption and excretion during the infusion of saline in a normal dog

\begin{tabular}{|c|c|c|c|c|c|c|c|}
\hline \multirow{3}{*}{$\begin{array}{l}\text { Urine flow } \\
c c . / \min .\end{array}$} & \multirow{3}{*}{$\frac{\text { Glom. filt. rate }}{c c . / \min .}$} & \multirow{3}{*}{$\begin{array}{c}\text { Plasma sodium } \\
m M / L\end{array}$} & \multirow{3}{*}{$\frac{\text { Urine sodium }}{m M / L}$} & \multicolumn{4}{|c|}{ Sodium } \\
\hline & & & & \multirow{2}{*}{$\frac{\text { Filtered }}{m M / \min .}$} & \multirow{2}{*}{$\frac{\text { Excreted }}{m M / \min .}$} & \multicolumn{2}{|c|}{ Reabsorbed } \\
\hline & & & & & & $m M / \min$ & \% filtered \\
\hline \multicolumn{8}{|c|}{10 cc. Saline per min. for preceding two hrs. and 30 mins., intravenously } \\
\hline $\begin{array}{l}8.93 \\
9.07\end{array}$ & $\begin{array}{l}80.0 \\
81.7\end{array}$ & $\begin{array}{l}151.2 \\
152.1\end{array}$ & $\begin{array}{l}90.5 \\
89.7\end{array}$ & $\begin{array}{l}11.49 \\
11.81\end{array}$ & $\begin{array}{l}0.808 \\
0.814\end{array}$ & $\begin{array}{l}10.68 \\
11.00\end{array}$ & $\begin{array}{l}93.0 \\
93.1\end{array}$ \\
\hline \multicolumn{8}{|c|}{$100 \mathrm{mg} . \mathrm{Hg}$ as Mercuhydrin, intravenously } \\
\hline $\begin{array}{l}11.58 \\
11.52 \\
15.60 \\
16.86 \\
17.06 \\
16.53\end{array}$ & $\begin{array}{l}86.5 \\
85.7 \\
83.0 \\
83.8 \\
83.4 \\
80.4\end{array}$ & $\begin{array}{l}152.1 \\
152.7 \\
153.6 \\
152.1 \\
152.7 \\
152.7\end{array}$ & $\begin{array}{l}114.1 \\
129.4 \\
126.7 \\
135.1 \\
136.9 \\
141.7\end{array}$ & $\begin{array}{l}13.16 \\
12.44 \\
12.10 \\
12.11 \\
12.10 \\
11.60\end{array}$ & $\begin{array}{l}1.331 \\
1.465 \\
1.962 \\
2.280 \\
2.335 \\
2.332\end{array}$ & $\begin{array}{r}11.83 \\
10.97 \\
10.14 \\
9.83 \\
9.76 \\
9.27\end{array}$ & $\begin{array}{l}89.8 \\
88.3 \\
84.8 \\
81.1 \\
80.6 \\
79.9\end{array}$ \\
\hline \multicolumn{8}{|c|}{$100 \mathrm{mg} . \mathrm{BAL}$, intramuscularly } \\
\hline $\begin{array}{r}10.33 \\
5.40 \\
6.33\end{array}$ & $\begin{array}{l}71.3 \\
85.2 \\
82.5\end{array}$ & $\begin{array}{l}154.5 \\
155.6 \\
156.8\end{array}$ & $\begin{array}{l}139.1 \\
124.6 \\
127.5\end{array}$ & $\begin{array}{r}9.82 \\
12.60 \\
12.39\end{array}$ & $\begin{array}{l}1.438 \\
0.674 \\
0.807\end{array}$ & $\begin{array}{r}8.38 \\
11.93 \\
11.58\end{array}$ & $\begin{array}{l}85.3 \\
94.7 \\
94.3\end{array}$ \\
\hline
\end{tabular}

Saline administered throughout at a rate of $10 \mathrm{cc}$. per min.

All urine collection periods 15 mins. in length.

nously in the dosage noted. Each experiment was terminated by the intramuscular injection of BAL. We would call attention to certain significant facts. Roughly 800 microequivalents of sodium per minute were excreted during the control periods of each experiment and during the periods following BAL. The filtration rate remained remarkably constant throughout all experiments. The administration of $50 \mathrm{mg}$. $\mathrm{Hg}$ increased sodium excretion to a peak value of 1,193 microequivalents per minute over the preceding control and the succeeding BAL levels; $100 \mathrm{mg}$. $\mathrm{Hg}$ increased it by 1,536 microequivalents per minute; $200 \mathrm{mg}$. $\mathrm{Hg}$ increased it by 1,754 microequivalents per minute.

A similar series of experiments performed on another dog, differing in the dose of mercury injected, is illustrated in Figure 5. It is evident that $60 \mathrm{mg}$. $\mathrm{Hg}$ increased excretion of sodium by 783 microequivalents per minute; $120 \mathrm{mg}$. $\mathrm{Hg}$ increased it by 1,564 microequivalents per minute;

TABLE II

Relation of the maximum depression of sodium absorption attainable with mercurial diuretics to the usual overall tubular absorption of sodium

\begin{tabular}{|c|c|c|c|}
\hline & Dog 1 & Dog 2 & Dog 3 \\
\hline $\begin{array}{l}\text { Saline infusion experiments } \\
\text { Peak sodium excretion after mercuhydrin } \\
\text { Mean sodium excretion before mercuhydrin and after BAL } \\
\text { Excess sodium excretion due to maximum mercurial effect }\end{array}$ & $\begin{array}{r}\text { microequis./min. } \\
2,520 \\
766 \\
1,754\end{array}$ & $\begin{array}{c}\text { microeguiv./min. } \\
2,440 \\
860 \\
1,580\end{array}$ & $\begin{array}{r}\text { microequiv./min. } \\
2,380 \\
849 \\
1,531\end{array}$ \\
\hline $\begin{array}{l}\text { Experiments without saline } \\
\text { Mean total sodium absorption }\end{array}$ & 8,212 & 9,008 & 8,972 \\
\hline $\begin{array}{l}\text { Sodium absorption susceptible } \\
\text { to blockage by mercurial } \\
\text { Total sodium absorption }\end{array} \times 100$ & $21.4 \%$ & $17.5 \%$ & \\
\hline
\end{tabular}




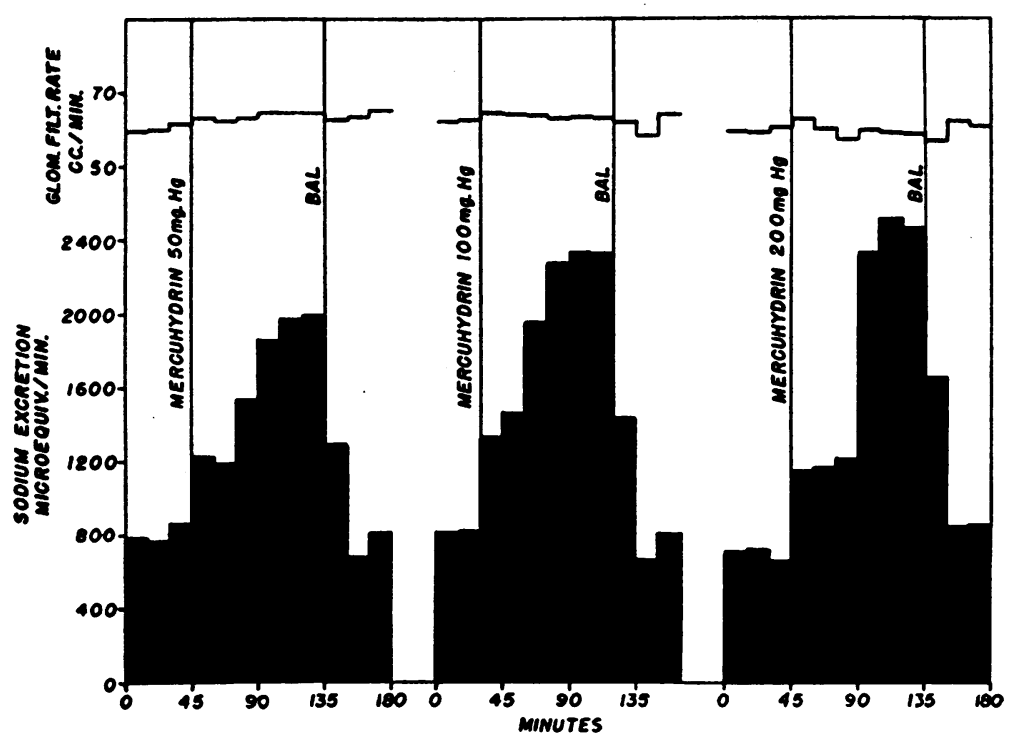

Fig. 4. Sodium Excretion in a Single Dog Given Graded Doses of MERCUHYDRIN

Saline infusion at $10 \mathrm{cc}$. per minute.

and $240 \mathrm{mg}$. $\mathrm{Hg}$ increased it by 1,580 microequivalents per minute. These doses represent about $1.5,3$ and $6 \mathrm{cc}$. of mercuhydrin respectively. This last dose is near a lethal one for a 16 to 18 kg. dog. Indeed, one animal died immediately following such a dose, despite the concurrent administration of $150 \mathrm{mg}$. of ascorbic acid.
The data obtained in the experiments just described, and in a similar series on a third dog, are summarized in Table II. The peak sodium excretion following mercuhydrin varied in these three animals only between 2,380 and 2,520 microequivalents per minute. The average excretion prior to the mercurial and following BAL varied

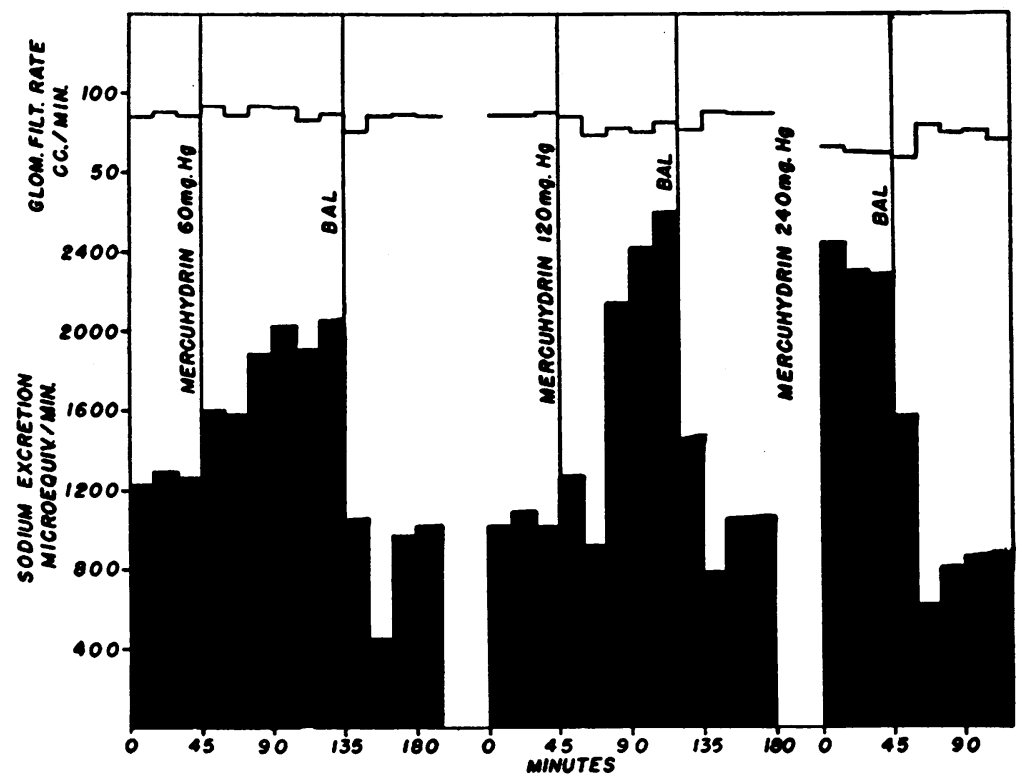

Fig. 5. Sodium Excretion in a Single Dog Given Graded Doses of MERCU H YDRIN

Saline infusion at $10 \mathrm{cc}$. per minute. 
within limits of 766 and 860 microequivalents per minute. ${ }^{5}$ The maximum increments in sodium excretion obtained by the administration of just sublethal doses of mercuhydrin therefore lie between 1,531 and 1,754 microequivalents per minute for these 16 to $18 \mathrm{~kg}$. dogs.

\section{DISCUSSION}

The results presented above indicate that the organic mercurial diuretics are capable of suppressing only a fraction of the renal tubular reabsorption of sodium. It seems reasonable to believe that this limiting response is reached when the reabsorptive system which is susceptible to their action has been completely blocked, so that further increases in dosage can produce no greater effect.

In order to relate the fraction of sodium absorption which is susceptible to the action of the mercurials to usual total sodium absorption, we have taken data from other experiments on these same three dogs in which no saline and no mercurial were administered. In these experiments total sodium absorption, which includes both proximal and distal moieties, amounted to 8,212 to 9,008 microequivalents per minute (Table II). Reduction of sodium absorption by 1,531 to 1,754 microequivalents per minute by the mercurial represents a blockage of 17.1 to $21.4 \%$ of average normal absorption determined in these control experiments. Were the reduction in sodium absorption expressed in terms of per cent of control absorption during the infusion of saline, values of the order of 13 to $15 \%$ would be obtained. Whatever the method of calculation adopted, the maximum depression of sodium absorption possible with these agents lies within the range generally attributed to the distal tubule, namely 13 to $33 \%$ of filtered sodium.

Reasoning alone from these data and from presently accepted views as to the magnitudes of proximal and distal tubular absorption, one can arrive at only one conclusion, namely, that mercurial diuretics depress the distal tubular absorption of sodium. If one wishes to make the additional assumption that no less than two functionally

5 Plasma sodium levels were slightly elevated during the saline infusion experiments, varying from 150 to 157 milliequivalents per liter but remaining fairly constant during any given experiment. distinct proximal tubular mechanisms exist, only one of which is mercury sensitive, our data may be brought into line with the view that these drugs exert their major action on the proximal segment.

Indeed certain functional and pathological evidences can be marshalled to support a concept of the proximal tubular action of mercurial diuretics. Thus Brun, Hilden and Raaschou (7) have demonstrated that these agents depress the secretion of diodrast and para-aminohippurate in man, a function presumably of the proximal segment. Similarly, Weston and his associates (8) have recently presented evidence that, in man, these agents depress the absorption of glucose, a function which is more securely established as a proximal tubular one. The inference might be drawn that mercury depresses all proximal tubular activities and that its effect on sodium absorption is merely an example of this same action. However, in the dog mercury depresses neither the secretion of para-aminohippurate (9) nor the reabsorption of glucose, ${ }^{6}$ yet it exerts its typical natriuretic action, facts which tend to negate the above argument. Pathological evidence on the other hand indicates that mercury acts most strongly as a protoplasmic poison in the proximal tubule (10). We would not suggest that mercurial diuretics are without specific actions on proximal tubular enzyme systems, rather that short of tissue injury they do not specifically depress those concerned with the absorption of sodium. Should the natriuretic action of these drugs be exerted proximally, one would expect that the larger part of the filtered sodium would appear in the urine when this effect was maximal.

In a series of experiments on a given animal or even among a group of animals of similar weight, the absolute levels of sodium absorption assigned to the distal tubule have been remarkably constant. One might interpret these findings as evidence for the concept of a limited distal tubular reabsorptive capacity for sodium as suggested by Wesson, Anslow, and Smith (2). However, from our data, it is equally possible that a fixed proportion of the filtered sodium is reabsorbed by the distal tubule. In our, experiments, the filtered load of sodium was maintained essentially constant. Absorption of a fixed proportion of this constant load cannot be distinguished from the

\footnotetext{
- Unpublished experiments from this laboratory.
} 
absorption of a constant absolute quantity of sodium. Theoretically, one might attack this problem by studying distal sodium absorption as a function of distal sodium load. Practically, we have been unable to achieve sufficient stability of filtration rate under varied sodium infusion. loads to render such a study feasible. Lability of filtration rate, particularly in the face of necessarily large doses of organic mercurials, imposes limitations on this experimental approach.

\section{SUMMARY AND CONCLUSIONS}

1. The depression of renal tubular absorption of sodium which can be produced by mercurial diuretics is limited. It is assumed that this limit is established when the absorptive system which is susceptible to depression by mercurials has been completely blocked.

2. The magnitude of the absorptive system so quantitated corresponds to the magnitude of distal tubular absorption as estimated by others.

3. It is inferred that organic mercurial diuretics depress the distal tubular absorption of sodium.

\section{BIBLIOGRAPHY}

1. Walker, A. M., Bott, P. A., Oliver, J., and MacDowell, M. C., The collection and analysis of fluid from single nephrons of mammalian kidney. Am. J. Physiol., 1941, 134, 580.
2. Wesson, L. G., Jr., Anslow, W. P., Jr., and Smith, H. W., The excretion of strong electrolytes. Bull. New York Acad. Med., 1948, 24, 586.

3. Pitts, R.F., and Alexander, R. S., The renal reabsorptive mechanism for inorganic phosphate in normal and acidotic dogs. Am. J. Physiol., 1944, 142, 648.

4. Lyons, R. H., Avery, N. L., and Jacobson, S. D., Effect of dehydration, produced by mercupurin, on the plasma volume of normal persons. Am. Heart J., 1944, 28, 247.

5. Chapman, D. W., and Shaffer, C. F., Mercurial diuretics. A comparison of acute cardiac toxicity in animals and the effect of ascorbic acid on detoxification in their intravenous administration. Arch. Int. Med., 1947, 79, 449.

6. Farah, A., and Maresh, G., The influence of sulfhydryl compounds on diuresis and renal and cardiac circulatory changes caused by mersalyl. J. Pharmacol. \& Exper. Therap., 1948, 92, 73.

7. Brun, C., Hilden, T., and Raaschou, F., Effects of mersalyl on the renal function. Acta pharmacol., 1947, 3, 1.

8. Weston, R. E., Grossman, J., Edelman, I. S., Escher, D. J. W., Leiter, L., and Hellman, L., Renal tubular action of diuretics. II. Effects of mercurial diuresis on glucose reabsorption. Federation Proc., 1949, 8, 164.

9. Berliner, R. W., Kennedy, T. J., Jr., and Hilton, J. G., Salyrgan and renal tubular secretion of paraaminohippurate in the dog and man. Am. J. Physiol., 1948, 154, 537.

10. Simonds, J. P., and Hepler, O. E., Experimental nephropathies. I. A method of producing controlled selective injury of renal units by means of chemical agents. Arch. Path., 1945, 39, 103. 